\title{
Research on the Style and Form Characteristics of the Utensils Design in Liao Dynasty
}

\author{
Congmei Zhao ${ }^{1}$ Xin Wang ${ }^{2, *}$ \\ ${ }^{1}$ Art Design College, Inner Mongolia Normal University, Hohhot, Inner Mongolia, China \\ ${ }^{2}$ School of Journalism and Communication, Inner Mongolia Normal University, Hohhot, Inner Mongolia, China \\ *Corresponding author. Email: 512076928@qq.com
}

\begin{abstract}
Taking the design of utensils in the Liao Dynasty as the research object, this paper classifies and analyzes the overall style of the utensil design of various crafts and materials, and the formal characteristics, and explores the historical background and cultural motivation of the design style of utensils in Liao Dynasty, so as to comprehensively understand and display the overall style of utensils in Liao Dynasty.
\end{abstract}

Keywords: Liao Dynasty, Utensils design, Style, Formal characteristic.

\section{INTRODUCTION}

In Chinese history, the Liao Dynasty established by Khitan people was in the active period of national exchanges and blending. The people of Liao Dynasty learned from all nationalities with an inclusive attitude, which made the Liao Dynasty achieve great development in politics, economy, science and technology, culture, crafts and other aspects, and show distinct characteristics of the times and nationalities. In particular, the design of utensils in Liao Dynasty is rich in variety, diverse in form and unique in style, being a model in the history of creation of ethnic minorities in northern China. In this paper, the design style of utensils in Liao Dynasty and its form characteristics are studied in depth.

Style refers to a unique feature of an artistic work as a whole. It is a relatively stable, more internal and profound expression through art works, and also essentially reflects the internal characteristics of the times, the nation or the artist's personal ideas, aesthetic ideals, spiritual essence and so on. [1] Also, it is characterized by fixed modeling and stable elements in art or design works. Form is considered to be the external shape, appearance or structure of an object.

The utensils discussed in this paper are mainly limited to the artistic creation design of Liao Dynasty, that is, "the production of plastic arts by means of handicraft industry involves all fields of people's life, and is directly related to people's clothing, food, housing, transportation and use." [2] The utensils made in Liao Dynasty were mainly gold and silver, ceramics, silk and jade. On the basis of focusing on the physical cognition and emotional cognition of the design style of utensils, this paper classifies and compares the visual form factors of utensils, such as modeling, decoration and color, so as to divide the above-mentioned utensils in Liao Dynasty into three styles: Khitan style, Central Plains Style and blending style.

\section{THE FORM CHARACTERISTICS OF UTENSILS OF KHITAN STYLE}

Khitan style refers to the stable and unique features of the Khitan nation in the fields of literature, art, design and arts and crafts from its origin to its demise. Its focus is on the embodiment of national characteristics and national emotions. Style is usually regarded as having a life cycle, that is, birth, youth, maturity, decline and death, so it is endowed with the characteristics of "early period", "middle period" and "late period". [3] More than 200 years since the establishment of Liao Dynasty was the prosperous period of Khitan style. The Khitan style generally referred to was mainly for this period. Later, the Khitan style of Western Liao Dynasty in the development of central and Western Asia was also based on this. 
Hegel once said: "when we encounter an art work, we first see what it directly presents to us, and then investigate its meaning or content." [4] Roger Frye, a British philosopher, once said: "the art treasures accumulated and inherited by human beings are almost all works whose form and structure are the main factors." [5] It can be seen that form is very important to works and people. From the perspective of form, style is represented by stable formal elements in art works. Similarly, the Khitan style of all kinds of utensils in the artistic creation design of Liao Dynasty is embodied by the visual form carriers such as modeling, color and decoration. The craftsmen of Liao Dynasty used the natural and artificial objects, which are popular in the daily life of Khitan people and reflect the national tradition and aesthetic interest, as design elements in the modeling, decoration and color of various utensils, so as to form the Khitan style or create the unique utensils of Khitan nationality.

In terms of modeling and decoration, the animals that Khitan people often contacted, such as horses, tigers, deer, dogs, sheep and haidongqing, are often used as prototypes or themes. At the same time, plant patterns, landscape patterns and cloud patterns are often used to show the natural scenery of northern grassland. "Chunshui Jade" that reflects the theme of falcon (falco rusticolus) catching Goose (Swan) and "Qiushan Jade" that reflect mountain, forest, tiger and deer are typical representatives of Khitan style. For another example, the Khitan forms in the gold and silver wares of Liao Dynasty are mainly reflected in the unique utensils of Khitan people with special purposes, namely, the rich and diverse burial utensils, horse harness, fishing and hunting utensils, ornaments, and utensils bearing chain. The shape of these utensils is not seen in other gold and silver ware, but the utensils are the most representative of the Khitan style and culture.

The utensils suitable for being carried are the utensils of Khitan style in Liao Dynasty. The main shapes are perforated cockscomb pot, long-necked bottle, drumstick-shaped bottle, Pankou longnecked pot, pot suitable for being weared and so on. They show some commonalities in modeling structure design: high body, small hole, curved flat abdomen, flat bottom. Some utensils have holes at the top or grooves and ring-shaped nose at the neck and abdomen. The main purpose is to tie ropes, being easy to carry. Among them, the most abundant and characteristic is the cockscomb pot, whose shape originates from the imitation of containers of leather of nomadic nationality. Some of the cockscomb pots are decorated with imitation leather buttons and leather ropes. The early cockscomb pots were shaped like two pieces of leather stitched together. In the details of decoration, the stitches of imitation leather stitches even appeared as decoration. ("Figure 1") This kind of utensils is designed and produced to adapt to the Qidan people's life style of taking horses and carts as their home and living by water and grass. It has the charm of nationality living on the horseback. The popularity of white-glazed porcelain in Liao Dynasty and the appearance of tri-colored ceramics in Liao Dynasty can reflect Khitan people's preference for color. Why do Khitans love whiteglazed ceramics so much? Shang Gang believed that it originated from the tradition of white grassland in the north. [6]

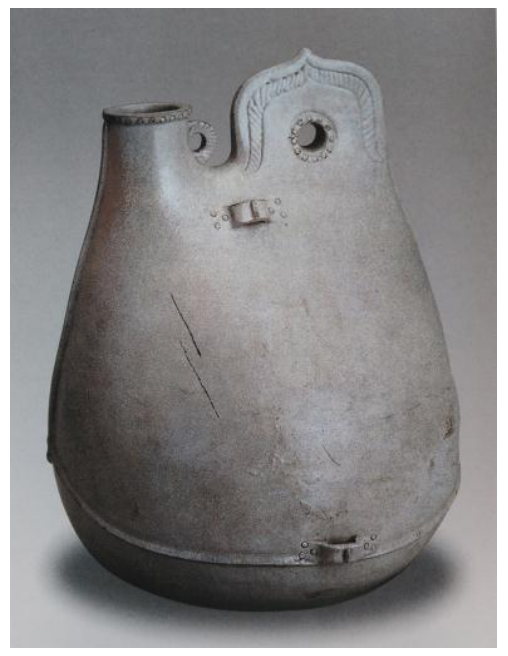

Figure 1 A kind of utensils of Khitan style in Liao Dynasty — white-glazed cockscomb pot.

\section{THE FORM CHARACTERISTICS OF THE UTENSILS OF THE STYLE IN THE CENTRAL PLAINS}

Since ancient times, the Central Plains has been the core region that dominates the development of the whole Chinese civilization. It is also the political, economic and cultural center in Chinese history. However, "Central Plains" is not a clear geographical concept. With the development of society, its scope is also expanding. In this paper, "Central Plains" is a relatively vague geographical concept, but also limited the time range. From the perspective of people of Liao Dynasty, the Central Plains in the broad sense refers to the territory of Tang Dynasty and Song Dynasty which confronted with Liao Dynasty. And the Central Plains in the 
narrow sense refers to the middle and lower reaches of the Yellow River which frequently contacted with Liao Dynasty.

The utensils of the style in Central Plains in this paper refer to the creatures with the Central Plains Style at that time within the scope of Liao Dynasty. At that time, the style of the Central Plains refers to the stable common fashion and aesthetic style of the times in the fields of literature, art, design and arts and crafts of the Tang Dynasty and the Northern Song Dynasty. In the frequent contacts with the Dynasties in the Central Plains, Khitan people took the initiative to learn and imitate the culture of the Central Plains, which made all aspects of the Liao Dynasty deeply influenced by the Han culture of the Central Plains and showed the characteristics of the culture in the Central Plains. Compared with Khitan style, the style of Central Plains in Liao Dynasty is a formal representation reflecting the cultural characteristics of Tang and Song Dynasties in Central Plains created by Liao people with Han nationality as the main body in their creation activities.

In the artistic creation design of Liao Dynasty, the utensils of the style in the Central Plains are expressed through the visual form carriers such as craft, modeling, color and decoration. A considerable part of the craftsmen in the Liao Dynasty came from the Central Plains, which makes the design of the Liao Dynasty have a deep origin with the Central Plains. The craftsmen of the Liao Dynasty imitated or directly used the technology of the Central Plains, and applied various forms of elements with the cultural connotation of the Central Plains loved by the people of the Central Plains to the similar or other crafts of the Liao Dynasty, which made the design of the creatures in Liao Dynasty, such as ceramics, gold and silver, jade, silk and so on, present a strong cultural flavor of the Central Plains.

Specifically speaking, in the aspect of learning the technology of Central Plains, the gold and silver ware of Liao Dynasty fully absorbed the technology of Tang and Song dynasties. In the Tang Dynasty, sheet metal was used for shaping, with flat engraving patterns or theme patterns hidden, gilded patterns and fished patterns on the bottom. This is also the method adopted by the vast majority of gold and silver wares in Liao Dynasty. Embossed flower decoration is a remarkable feature of gold and silver ware in Song Dynasty. The embossed craft in Song Dynasty is characterized by high relief, multi-level effect and strong three- dimensional sense. This kind of embossed craft and decoration style in Song Dynasty appeared on gold and silver wares in the middle and late stage of Liao Dynasty. In the silk industry of Liao Dynasty, dyeing technology and products popular in Central Plains, especially in Tang Dynasty, and clay gold printing fabric popular in Northern Song Dynasty were all popular in Liao Dynasty. In terms of modeling, the types and modeling of gold and silver wares in the Liao Dynasty are the most common in the Tang Dynasty, mainly focusing on bowls, plates, cups, boxes, pots, etc. ("Figure 2") Bionic and changeable modeling is a prominent feature of gold and silver wares in the Song Dynasty, which was also absorbed and applied in the Liao Dynasty. The jade belts, hairpins, rings, bowls, calices, bowls, boxes, pots and bi (a piece of jade with hole in center) of the Liao Dynasty are all traditional shapes of the Han nationality. In the aspect of decorative patterns, the decorative themes of various utensils in Liao Dynasty can be roughly divided into plants, aquariums, birds, exotic animals, figures and so on, and their decorative themes and organizational forms more or less reflect the formal characteristics of the Central Plains.

The formal characteristics of ceramics in the style of the Central Plains in Liao Dynasty are mainly reflected in the learning, imitation and inheritance of the ceramics of Tang and Song Dynasties from the aspects of technology and decoration, modeling and use, pattern and glaze color, and embody the obvious style and characteristics of the ceramics of Tang and Song Dynasties. The porcelain craftsmen in the hinterland of Liao Dynasty mainly came from the northern Central Plains, especially from the Xing Kiln and Ding Kiln in Hebei Province. The porcelain-making tradition in Yanyun area can be traced back to the Tang and the Five Dynasties. Therefore, the production technology of porcelain industry in Liao Dynasty was greatly influenced by the Five Dynasties and the Northern Song Dynasty. It can be roughly divided into three systems in the Central Plains: one is similar to the Ding kiln's white porcelain system; one is similar to the Cizhou Kiln's white-glazed painting and drawing system, and the other is similar to the Tang Dynasty's lowtemperature lead glazed pottery system. [7] The style of Central Plains occupies a large proportion in the ceramics of Liao Dynasty, and its shape almost imitates the most common shape of life porcelain in Tang and Song Dynasties. From eating utensils to entertainment utensils, religious 
porcelain to architectural pottery, the style of Tang and Song Dynasties in the Central Plains were fully imitated, most of which were practical utensils. Some patterns appeared frequently on ceramics of Liao Dynasty, such as peony, lotus, chrysanthemum, children-playing, dragon pattern, fish pattern and so on. Although some of the patterns have strong Khitan style, these decorative themes and patterns are also popular in the porcelain of the Five Dynasties and Northern Song Dynasty. In terms of glaze color, Khitan people prefer white porcelain, and many kilns imitate white porcelain of Ding Kiln.

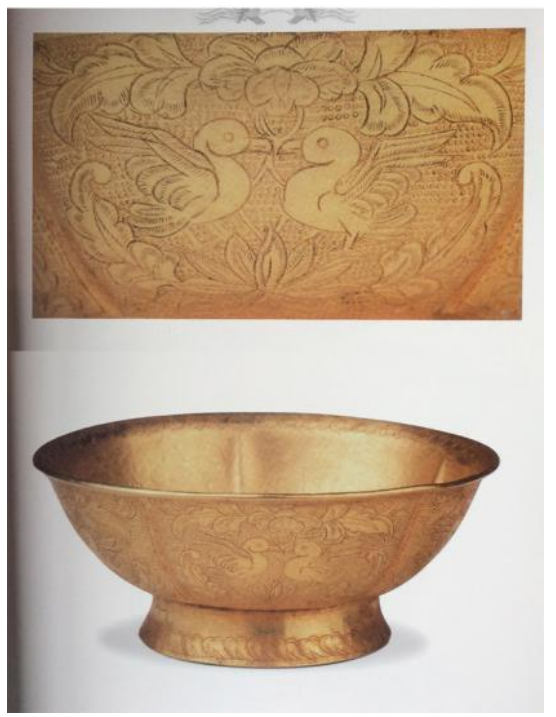

Figure 2 A kind of utensils of the style of Central Plains in Liao Dynasty - golden cup with flower chisel.

\section{THE FORM CHARACTERISTICS OF THE UTENSILS OF THE BLENDING STYLE}

The blending has the meaning of melting and exchange, and refers to the integration of two or more different things. Integration emphasizes the conscious and selective absorption and reference of external things, and the integration and neutralization of ideas and ability. Integration also reflects a process and result of inclusive innovation. The blending style of Liao Dynasty refers to the fact that during the 200 years since the founding of the Liao Dynasty, people of Liao Dynasty absorbed and borrowed foreign cultures and integrated them with Khitan national culture, thus presenting a unique form and features in the fields of literature, art and design. Integration needs time. The blending style of Liao Dynasty exists not only in the integration and innovation, but also in the process of integration and evolution. Therefore, this paper focuses on the whole process of the integration of utensils in Liao Dynasty, emphasizing the two aspects of the blending of cultural elements in the visual form of utensils and the concept of the times and spiritual essence of Liao people reflected by utensils. National integration is the trend of historical evolution. Khitan culture derives more new connotations and shows new styles in the blending of national customs, Han customs and $\mathrm{Hu}$ customs.

The blending style of all kinds of utensils in the artistic creation design of Liao Dynasty is mainly manifested in the following aspects: combining the foreign cultural elements and Khitan national cultural elements in various ways, creatively using them in the modeling and decoration of various utensils, and showing a style of inheritance and innovation which is different from the prototype. On the one hand, on the basis of imitating one or more styles of utensils modeling, the original modeling is partially deformed. For example, the gold-plated belt with rings unearthed from tombs of Liao Dynasty was influenced by the similar utensils of the Tang Dynasty. The shapes were very similar, and the rings and holes were large round. However, in the Tang Dynasty, the ring was divided into two parts, while in the Liao Dynasty, the ring was integrated, which should be an improvement in the early Liao Dynasty. The typical cup with handle among the gold and silver wares of Liao Dynasty can be found similar in the shape of Sogdian cup, but it has been improved. For another example, the octagonal shape folding ridge and the lion training pattern of the $\mathrm{Hu}$ people in the dish of Liao Dynasty have strong cultural elements of the $\mathrm{Hu}$ culture in the western regions, but its function is to wash the brush, which is a necessary study tool in the Central Plains and an important carrier and symbol of the culture in the Central Plains. Khitans integrate these cultural elements of different nationalities and regions into their own utensils design, showing their tolerant and open attitude.

On the other hand, it is necessary to absorb some or more styles of patterns and decorative forms, and make appropriate modifications and replacement according to national preferences, or decorate various creations with similar or variant patterns. For example, in the Tang Dynasty, most of the patterns on silk were a pair of deer, horse, sheep, birds and trees, while in the Liao Dynasty, patterns of a pair of fish, capricorn and flowers were developed. In addition, according to the aesthetic 
tendency of Khitan people, different styles of modeling and decorative patterns are combined on an object to form a new visual effect. For example, the pot folding shoulder among the gold and silver wares of Liao Dynasty has typical Sogdian and Turkic modeling forms, while the wares are carved with patterns with strong culture of the Central Plains, forming a blend of styles. Another example is the gold-plated silver pot "filial son" unearthed from Yelvyu's tomb in the Liao Dynasty. Its shape is Turkic, and its decoration and inscription are in the style of the Central Plains. On the surface of the Sutra bundle with Knight pattern unearthed from Baita of Qingzhou, the pattern combines the hunting pattern of Khitan people with Buddhist pattern and Sassanian pattern. ("Figure 3") Another example is the double-hole cockscomb pot in the early Liao Dynasty. Both sides of the ampulla are engraved with patterns, among which the most common pattern is rolled grass in the Tang Dynasty. The pattern inherits the decorative form of circular rolled grass in the Tang Dynasty, but it is obviously different from grass in Tang Dynasty. The stylized structure is more free, vivid and powerful.

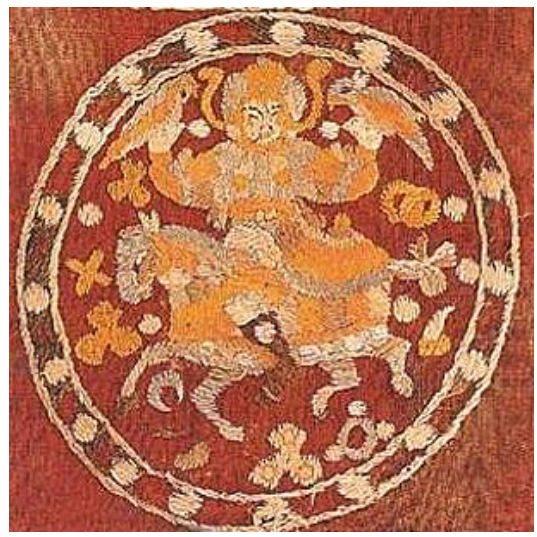

Figure $3 \mathrm{~A}$ kind of utensils of the blending style in Liao Dynasty - Sutra bundle with knight pattern.

\section{CULTURAL ORIGIN OF THE STYLE AND FORM CHARACTERISTIC OF UTENSILS}

The design styles of utensils in Liao Dynasty are diverse. From the perspective of form characteristics, modeling, decoration, color and other elements not only have national characteristics, but also contain multi-cultural factors. They not only inherit the national traditional utensils, but also innovate according to the needs of time and place. This kind of inheritance and innovation reflects the Khitan people's broad-minded and eclectic attitude towards creation, reflecting the deep historical background and cultural roots.

First of all, the Liao Dynasty was established side by side with the Tang Dynasty, the Five Dynasties, the Northern Song Dynasty and the Western Xia Dynasty, which had a vast territory. During the period of the Liao Dynasty, there were confrontational dynasties and regimes, objectively promoting the national integration and cultural exchange. Liao Dynasty also had some trade with the western regions through the grassland silk road. Moreover, the border between Liao nationality and Han nationality is at the junction of nomadic culture and farming culture. The two cultures conflict, adjust and integrate in the production and life of people of Liao Dynasty. This historical and geographical space broadened the vision of people of Liao Dynasty, enriched the world of people of Liao Dynasty, and made them develop in the process of communication with various nationalities.

Secondly, from the perspective of cultural origin, the cultural essence of the design style and form characteristics of utensils in Liao Dynasty is the openness of Khitan nomadic culture. Qian Mu, a historian, once said: "from its source, human culture has three types, that is, nomadic culture, farming culture and commercial culture. Nomadism and commerce start from internal deficiency, and it needs to be sought from outside, so they are mobile and enterprising. Farming can realize the selfsufficient effect without external demands, so it is static and conservative." [8] The openness of nomadic culture in Liao Dynasty stimulated the sustainable development of utensils design in Liao Dynasty through learning and imitating, contacting and blending foreign multi-culture.

\section{CONCLUSION}

The design of utensils in Liao Dynasty presents Khitan style, the style of Central Plains and blending style. Its form characteristic is reflected by visual form carriers such as modeling, color, decoration and craft performance. According to different types and characteristics of utensils such as gold and silver, ceramics, silk and jade, it shows various forms. The style and formal characteristics of the utensils design in Liao Dynasty not only reflect the national confidence, aesthetic interest, characteristics of the times, principles of handling affairs, but also reflect the rational attitude of people of Liao Dynasty towards inheritance and 
innovation, which is rooted in Khitan nomadic culture.

\section{AUTHORS' CONTRIBUTIONS}

Congmei Zhao is responsible for writing the paper, and Xin Wang contributed to revising and editing it.

\section{REFERENCES}

[1] Editor-in-Chief Committee of Encyclopedia of China. Encyclopedia of China - Fine Arts (1). Beijing: Encyclopedia of China Press. 2003: 228-229. (in Chinese)

[2] Shang Gang. The New History of Chinese Arts and Crafts (Second Edition). Beijing: Higher Education Press. 2007. (in Chinese)

[3] [English] John Walker, Judy Attfield. Design history (Zhou Dandan and Yi Fei trans.), Nanjing: Jiangsu Fine Arts Publishing House. 2011: 135. (in Chinese)

[4] [Germany] Hegel. Aesthetics. (Zhu Guangqian trans.), Beijing: The Commercial Press. 1979: 10. (in Chinese)

[5] Zhu Liyuan. History of Modern Western Aesthetics. Shanghai: Shanghai Literature and Art Publishing House. 1996: 341. (in Chinese)

[6] Liu Fengjun. Ancient Chinese Ceramic Art. Jinan: Shandong Education Publishing House. 1990: 117. (in Chinese)

[7] Qian Mu. Introduction to Chinese Cultural History. Beijing: Jiuzhou Publishing House. 2013: 121. (in Chinese) 